\title{
20. Aesthetics and Morality in Kant and Confucius: A Second Step
}

\section{Christian Helmut Wenzel}

In the framework of his transcendental philosophy Kant strictly separates morality from aesthetics. The pleasure in the good and the pleasure in the beautiful are two different kinds of pleasure (zwei Arten des Wohlgefallens). As a consequence, a moral act as such cannot be beautiful. Only in a second step does Kant indicate possible connections between morality and aesthetics in his comments on aesthetic ideas, symbolism, the sensus communis, and education in general. In Confucius by contrast, we do not find such a radical separation between beauty and morality. He talks of humaneness (ren, 仁) and ritual ( $l i$, 禮). Projecting Kantian notions into the Analects, "beauty" seems to slide between the two and "moral" acts appear to be beautiful. One might wonder whether Confucius missed a point, or whether Kant overdid the separation. Or maybe both conceptions, of morality as well as of beauty, cannot so easily be translated from one philosophical tradition, or mind, to the other, and there is nothing like ren and $l i$ in Kant. In this essay I ask whether there is an "inner" and an "outer" in Confucius, and I introduce Kant's notion of "subjective purposiveness" and relate it to the Confucian notions of dao (道) and tian (天) as well as to ren and li.

Reading the Analects, one easily feels that Confucius trusts in certain correlations between the inner and the outer, where I think here of the inner as moral feeling or ren (humaneness, benevolence) and of the outer as $l i$ (ritual). ${ }^{1}$ We should practice (outer) rituals to acquire the right (inner, moral) attitudes. One feels this suggestion is based on the belief that outer performances can make us aware of inner feelings for human values. Of course, there is no guarantee: "The Master said, Clever words and a pleasing countenance-little humaneness [ren]

1 My association of the inner with moral feeling or ren is intended to be loose and preliminary. Differences and similarities should become apparent in the course of this essay. 
there." 2 Things can go wrong, and we all know that. Confucius certainly did. Nevertheless, some kind of trust in positive correlations can always be felt throughout the Analects: "The Master said, A human being who lacks humaneness-what is ritual to someone like that? A human being who lacks humaneness-what is music to someone like that?"3 Music and ritual must be performed with the right attitude, because only through such an attitude do they acquire their true meaning and value. Confucius believes in outer practices leading to the development of such inner attitudes. The performance of music, archery, and other forms of ritual will lead one to realize, see, and develop the right kind of moral views and feelings. For this reason, and with this hope, Confucius recommends education and learning in general. The outer is not merely a sign but also a stimulus for development of the inner. This is what I mean by "trust in positive correlations".

My talk of the "inner" and the "outer" may seem imported and projected here. One might think Confucius himself does not speak in such terms. " He does not speak of "mental representations" or "souls". But he knows of deceit and mere outward appearance; that is all I need here to feel justified in importing these terms of an inner and an outer for the moment. ${ }^{5}$

Comparable, one might think, to the correlation of beautiful ritual and moral attitude in Confucius, Kant talks of a "beautiful soul" (eine schöne Seele) $(5: 300[\$ 42])$ and of "beauty as a symbol of morality"

2 Confucius, The Analects of Confucius, tr. Burton Watson (New York: Columbia University Press, 2007), 1:3.

3 Confucius, $3: 3$

4 But see 4:17 ("reflect on your own account") and 5:27 ("anyone who can ... look inside himself, and put the blame there ..."). Confucius does talk about the inner, in some way. How, and to what degree, has to be worked out.

5 Hence I tend to side with Benjamin Schwarz against Herbert Fingarette. See Benjamin I. Schwarz, The World of Thought in Ancient China (Cambridge, Mass. and London: Harvard University Press, 1985), 72-4. For a passage pointing out sources in Herbert Fingarette, Benjamin Schwartz, Henry Rosemont, and Chad Hansen, discussing Confucius' concern (or lack of concern) for people's internal psychological life, see Philip J. Ivanhoe, Ethics in the Confucian Tradition (Indianapolis/Cambridge: Hackett Publishing Company, 2002), 170, n.22. Also Tu Wei-Ming, Humanity and Self-Cultivation: Essays in Confucian Thought (Boston: Cheng \& Tsui Company, reprinted 1998; Lancaster-Miller Publishers, 1978) freely talks of an inner and an outer, of ren as an "inner morality", a "self-perfecting" and "self-fulfilling process of an individual", and a "principle of inwardness", and of $l i$ as its "externalization" (9-13, see also $17-30)$. 
$(5: 351[\$ 559])$. Kant even provides a whole theory that allows us to explain how beauty and morality are linked and why and how this link is merely an indirect one, thus leaving, and even creating, room to account for failed correlations. According to Kant, beauty and morality are based on acts of reflection where we take ourselves as subjects in general, abstracting from personal considerations. Pleasure in beauty must be disinterested and felt by us as human beings as such. Only then are we justified in claiming universal validity for our judgment of taste. Similarly, the morally good is realized in acts based on universality considerations regarding rules and principles. ${ }^{6}$ This similarity, or isomorphism, between aesthetic and moral acts of reflection can be imagined to be underlying some of Confucius' intuitions. In Analects 3:8, for example, he writes:

Zixia asked, saying,

Her artful smile engaging,

Lovely eyes in clear outline,

Colors on white ground,

What do these lines mean?

The Master said, The painting comes after the white background.

Zixia said, So ritual comes afterward?

The master said, Shang (Zixia) is the one who reads my meaning. At last I have someone to discuss the Odes with.

I read this passage as a way of pointing out ren: three items are given and the fourth, ren, has to be figured out: As the lovely (mei, 美) eyes are related to the white ground, so is ritual to ren. The latter is in both cases a prerequisite for the former; $a$ stands to $b$ as does $c$ to $x$, where $x$ is the unknown element: $a: b=c: x$. Without the white background $(b)$, you cannot draw the eyes in clear outline $(a)$, and without ren $(x)$, ritual (c) does not make sense. The eyes are beautiful only against the white background and ritual must be performed with the right attitude. It is the white background in relation to the colorful and lovely eyes that should remind the reader of ren as a prerequisite for ritual and its beauty. The analogy is an aesthetic one. Beauty serves morality by being a visible symbol for it. This way of putting it fits the Kantian conceptual framework of beauty being the symbol for morality.

6 See Christian Helmut Wenzel, An Introduction to Kant's Aesthetics: Core Concepts and Problems (Malden, Massachusetts and Oxford, England: Blackwell, 2005), 113-9, for an exposition of beauty and morality and their symbolic relationship according to Kant. 
But Confucius does not talk about "acts of reflection" or a "free play of our faculties of cognition". He is not a philosopher like Kant. Why and how morality is a prerequisite for beauty of ritual, such as archery or music, remains unclear. Nevertheless, the picture Confucius offers has its charm (not in Kant's sense of Reiz, though usually translated as "charm"; 5:223 [\$13]). The eyes, colors, clear outline, and white ground all belong to the realm of the visual and aesthetic, whereas ritual and ren belong to the moral realm. But there is no such strict separation here. Ritual itself is aesthetic, and the white ground is given a moral tone. Both ritual and ren appear as being beautiful. Kant would, strictly speaking, resist such a view, or move, and allow for it only in a symbolic way. Moral feelings cannot be perceived and therefore cannot be beautiful. But, on second thought, maybe ren is not quite the same as moral feeling.

Another connection between the moral and the aesthetic, if we continue to allow ourselves to import these terms here, can be seen in a passage relying on the notion of harmony (he, 和): “The Master said, What ritual values most is harmony. The Way of the former kings was truly admirable (mei) in this respect."7 But what exactly is meant by "harmony" here? The context talks of loyalty, trustworthiness, and filial behavior as being of primary concern, whereas ritual, the arts, and government come second. ${ }^{8}$ I therefore think the harmony of inner attitudes is meant here and gives the ritual its beauty. Such beauty has to "shine through". But how is this supposed to work? Rituals are performed in the form of acts and processes that unfold in time and space. Seen from the outside, one has to know, or somehow "see", that they are not superficial and merely punctually performed but that they reflect and are the result of the right inner attitude. How does one "see" such an inner attitude from the outside? Even seen from the inside, in first-person perspective, when performing rituals oneself, one is led, as one might be surprised to find out, to the same question: One often imagines oneself as being seen and regarded by others. One sees oneself through the imagined eyes of others and thus relies on others to see oneself. The inner is accessible in first-person perspective partly through imagining a second- or third-person perspective. Of course one can go wrong, or even deceive oneself. There is room for vanity. But that is another question.

7 Confucius, 1:12.

8 See Confucius, 1:2, 1:4, 1:7, 1:11, and 1:13. 
"Zixia asked about filial devotion. The Master said, The difficult part is the facial expression." Again, Confucius trusts in the correspondence. The harmony that "ritual values most" (quoted above) can therefore be understood as the outer appearance of an inner harmony, similar to the facial expression that should be the outer appearance of the proper inner attitude of filial devotion. Confucius' trust in education through ritual is based on such inner-outer correspondences. Another passage that I read in this way is 4:1: "The Master said: Humaneness is the beauty of the community." In opposition to the interpretation suggested so far, an interpretation that takes harmony and beauty as being based on inner qualities such as loyalty, trustworthiness, and filial behavior, one could quote $3: 25$. There Confucius talks of Wu music as being "perfect in beauty, but not perfect in goodness" and thereby presupposes the possibility of beauty being separated from inner qualities. ${ }^{10} \mathrm{Appa}-$ rently something can be beautiful without the right inner qualities shining through. But I think 1:12 and 4:1 are not meant in this way. ${ }^{11}$ In fact, they point out the (ideally) right correspondence between beauty and goodness and the desirability of that correspondence.

Another example of a link, tacitly assumed between the inner and the outer, can be found in 6:16: "The Master said, If you have the good looks (mei) of Song Zhao but lack the eloquence of Invocator Tuo, you'll have a hard time escaping blame in the world today." Confucius lived in difficult times, when having good looks and even being a good person were often not enough. Although it is not something that Confucius approves of, he recognizes it as an unfortunate fact that sometimes you have to argue and be eloquent if you want to be successful and escape blame "in the world today". The next sentence, 6:17, makes this clearer: "Who can go out of a house without using the door? Why does no one use this Way of mine?" Although the right Way seems so obvious to Confucius, it is not practiced at his time. ${ }^{12}$

9 Confucius, $2: 8$.

10 For further comments on 3:25, see Christian Helmut Wenzel, "Beauty in Kant and Confucius: A First Step", Journal of Chinese Philosophy 33 (Jan 2006), 95108, here 98-9.

11 For an interpretation of both 1:12 and 4:1, see Wenzel "Beauty in Kant and Confucius: A First Step", 99-102.

12 The Analects of Confucius: A Philosophical Reading, trs. Roger T. Ames and Henry Rosemont, Jr. (New York: Random House, 1998), refers to the Dingzhou text and gives another translation of $6: 16$, preferring "humaneness" to "eloquence". But I think we do not need to make such an adjustment. Confucius is not 
How far can we go with our talk of the "inner" in Confucius? How far are we justified in doing so? And how far can we go with our talk of "morality" (Moral) and "beauty" (Schönheit), in Kant's sense of these terms, in our interpretation of Confucius? If we say, as I just did, that a moral attitude - of filial piety, say—has to "shine through" and to give an act or a ritual performance its "beauty", Kant would not agree. ${ }^{13}$ Firstly, to him, within his transcendental philosophy, only objects of the outer senses can be called "beautiful". Secondly, if a performance was beautiful, the grounds for this could not be moral ones, such as moral attitudes that somehow "shine through". Beauty, Kant insists, must stand on its own feet. It must have its own specifically aesthetic justifying grounds, independently of morality. The "free play" of imagination and understanding must not rely on moral considerations, not even on similarities to moral reflections. The similarity must be gratuitous. Only then, Kant thinks, is it the case that beauty can serve morality. The link between the two is based on an essentially gratuitous isomorphism between reflections underlying judgments of taste and reflections underlying moral judgments. Aesthetic universality cannot be reduced to moral universality, in judgment as well as in reflection. Something cannot be beautiful because it is good, nor can it be good because it is beautiful.

But maybe we have already made a mistake at the beginning, by identifying ren with morality (Moral) and the inner, and by identifying mei with beauty (Schönheit). ${ }^{14}$ Firstly, morality is a rather abstract notion in Kant. It belongs to reason: practical reason (praktische Vernunft). Kant lived at the time of the Enlightenment that stressed autonomy and rational abilities, and already in Aristotle we find strong links between morality and rationality, because theory and theoretic contemplation

happy with his time and does not approve of the situation where one unfortunately often needs eloquence as well. He does not recommend eloquence.

13 For a discussion of the relation between ren and $l i$ in general, not necessarily in relation to beauty, or mei, see Tu Wei-Ming, Humanity and Self-Cultivation, and Shun Kwong Loi, "Rén 仁 and Lî 禮 in the Analects", in: Bryan W. Van Norden, Confucius and the Analects: New Essays (New York: Oxford University Press, 2002), 39-52. Tu emphasizes the creative, dynamic tension between the two. Shun discusses two extreme positions, one seeing $l i$ as defining ren and thereby making the latter depend on the former, the other taking $l i$ as merely instrumental for developing ren and thereby giving ren a more independent status. Shun himself suggests an intermediate position.

14 On ren, see Confucius $1: 3$ and $3: 8$; on mei, see $3: 8,1: 12$, and $6: 16$. 
$\left(\vartheta_{\varepsilon \omega \rho} l \alpha\right)$ always figure in the background. Both Aristotle and Kant were interested in the natural sciences. Nothing like this can be found in Confucius. Secondly, Confucius did not consider problems with the conceivability of freedom of will versus physical determinism, especially as we find the latter against the background of Newton's physics. Confucius therefore did not have to venture toward something like transcendental philosophy in order to cope with the problem of free will. Thirdly, morality assumes a rather intangible character in Kant, and one might wonder whether this is so in Confucius as well. According to Kant, one is never sure whether one has really performed a morally good act or whether some hidden selfish interest was involved. The moral person has to be excluded from the deterministic, physical world. It shrinks to a mere point. Confucius also expresses some kind of reservation or doubt regarding our knowledge of humaneness (ren) - he often says things such as: "I don't know if he is humane" and "I don't know how he can be called humane." 15 But he is referring to the humaneness of others, not his own. Whether he has doubts regarding himself, in his own case and in first-person perspective, is another question. ${ }^{16}$

In spite of these fundamental differences and the problems of commensurability they create- and I think they indeed do create such problems-I nevertheless think it is fruitful to introduce a central notion from Kant's third Critique into the Analects: the principle of purposiveness (Zweckmäßigkeit). The subjective principle of purposiveness is the most important "moment" of the four moments of the judgment of taste, and it is supposed to help bridge the gap between nature and morality in Kant. The principle of purposiveness appears in three "modes", as I would like to call it: It appears subjectively in beauty, objectively in our understanding of organic nature, and transcendentally in the natural sciences. In all three modes we find, to put it very generally, something fitting something else, as if by chance, and without us being able to account fully for why we find things the way we do. In aesthetics, we can read such experiences as signs. Kant speaks of "hints" (Winke), telling us that we fit into nature and that our hopes to realize our moral ideas in this world are not out of place. This should sound familiar, in

15 Confucius, $5: 8$ and $5: 18$.

16 In 7:33, Confucius remarks "The title of sage or humane man-how could I dare lay claim to such?" But this is less an expression of doubt, and more a sign of modesty. 
some way, to anyone having read the Analects. What is more, the Kantian principle of purposiveness can be seen as giving support to Confucius' trust in rituals, as I will explain in the following.

When judging an object to be beautiful, we find it purposive for a free play between imagination and understanding, a play that is, firstly, pure (i.e., free from personal, individual interests), and secondly, harmonious, as would be required for cognition in general. The play of the faculties transcends the individual and opens horizons for cognition and discovery. ${ }^{17}$ For Kant, even the pleasure it gives rise to is based on this feature of transcending the individual. This is part of what makes it an a priori pleasure. We contemplate and feel the pleasure as human beings in general, as human beings qua human beings. The symbolic link with morality is then based on this feature of generality; for Kant this is not mere empirical generality but even a priori universality. But there is more. On an even higher level, we take an "intellectual interest" in beauty by taking beauty as a hint that tells us that our moral hopes might not be frustrated. ${ }^{18}$

Talk of intellectual interest in beauty applies primarily to beauty of nature and not to beauty of art. But then, as the latter is the product of genius and genius is a gift of nature, both the hint and the intellectual interest can be found in beauty of art as well. This is relevant to our discussion of Confucius, because we can ask how "natural" a ritual possibly can be. We can mistrust rituals, pointing out that they are artificial creations of humans and that they can go wrong. This worry, in turn, could be countered by saying that ritual can be the product of genius, where genius is, in a Kantian way, inspired by "nature", or, in a Confucian way, by Heaven (tien). Nevertheless, we then still have the problem of determining in particular situations what is, and what is not, an act or suggestion of genius, or Heaven.

Confucius emphasizes ritual, because he wishes to re-establish order at a time of war and the disappearance of traditional values. Ritual has a practical purpose. But it is also harmonious (he) and beautiful (mei). This harmony is mainly social harmony, but I think it also has a cosmological

17 See Christian Helmut Wenzel, "Beauty, Genius, and Mathematics: Why Did Kant Change His Mind?”, History of Philosophy Quarterly 18 (Oct 2001), and Wenzel, An Introduction to Kant's Aesthetics, 133-40, for an account of beauty and genius in mathematics within the Kantian framework. Even in mathematics, I think, some kind of freedom matters.

18 For Kant on our "intellectual interest” in beauty, see 5:298 (\$42). 
dimension. Although Confucius is mainly aiming at inter-subjective uniformity between human beings, as well as conformity with the traditional rules, time and natural circumstances have to be taken into account as well. In Kant, it appears, prima facie, very differently: the harmony in question here, aesthetic harmony, is a harmony between our cognitive faculties, imagination and understanding. This harmony is in us, in our ways of perceiving, understanding, conceptualizing, and forming ideas. In Kant it is an intra-subjective, in Confucius a more inter-subjective harmony that matters-at least so it might seem so far.

Of the three modes of purposivness (subjective, objective, and transcendental), only the first is linked to beauty. The other two are related to teleology and the empirical natural sciences. Only the first is helpful in seeing beauty as a symbol of morality, whereas the other two modes point toward nature. Nevertheless, the element of chance and gratuity can be found in all three. We find ourselves fitting into nature on a gratuitous basis, and this again matters for Kant's concept of beauty. ${ }^{19}$ How does Confucius fare in comparison with this?

Compared with he and mei, Confucian tian and dao figure more cosmologically. Although dao should be realized and practiced by us, it exists already in nature outside. Human harmony and beauty are derived from it. What comes closest to this in Kant might be the principle of purposiveness. Although this principle is a priori and part of our faculty of judging, and therefore in us (as is typical for transcendental philosophy), it nevertheless forms a bridge between nature as being given and nature as being systematically understood. It underlies empirical order (the second and third modes of purposiveness). Kant's principle of purposiveness thus offers a possibility for an explanation of the role of tian and dao in Confucius. It can be seen as giving grounds for trust in rituals. Of course, again, there is no guarantee. Rituals can go wrong.

The harmony Confucius is aiming at is a harmony of dao, and we can find this harmony in three ways: (1) between human beings, (2) in relation to traditional values and rules, and, though possibly to a lesser extent, (3) with nature as it is given. The first (morality) and the last (nature) can be seen to figure also in Kant's notion of purposiveness. But

19 I do not know how much Kant would have changed his views had he known of the evolutionary theories that we know today. He certainly foresaw many of their features, and it is remarkable that he interpreted the "beauty of nature" as being based on a "blind" and mechanical, and not a purposefully designed, nature (see the recent work of Alexander Rueger on this matter). 
the second (tradition) we find only in Confucius and not in Kant. Confucius had faith in the past; Kant did not. ${ }^{20}$ Kant trusts more in reason and the future, whereas Confucius believes in the ways of the past and their power to re-introduce dao. Confucius models his ideas on a concrete, though past, reality. Kant proposes abstract principles for the future. ${ }^{21}$ Confucius trusts in ritual and the idea of the gentleman as a model for emulation. It is therefore not surprising that aesthetics and ethics are more closely related in his world view than in Kant's: aesthetics is about what we can see, or otherwise perceive, in the Greek sense of the word "aesthesis" ( $(\alpha / \sigma 9 \eta \sigma / \zeta)$, and in some sense we can see and perceive ritual performances and the behavior, manner, conduct, and comportment of a gentleman. We can see a model such as a gentleman or a ritual performance in time and space, but we cannot see the categorical imperative. The latter is abstract and involves reflection about maxims and their universalizablility. Kant's interest in mathematical laws of nature had an effect on his conception of morality, placing him in a position more distant from that of Confucius. In his aesthetics

20 For a brief presentation of views by Fingarette, Hall and Ames, and Roetz that do not see Confucius as really turning to the past, see Ivanhoe, Ethics in the Confucian Tradition, 5-10. This would count against the view presented here. Furthermore, Kant also saw values in the traditions from the past. He recommended setting up standards for poetry in Latin, because this language does not change any more and therefore provides stability. He also recommended discipline over genius whenever the latter tends to be exaggerated and superficial. But I think his trust in the progress of the sciences and in the power of reason and autonomy was stronger than his love for the past, and here I see the difference between him and Confucius, in whose views we do not find the natural sciences play such a role and have such a driving force.

21 No wonder Fingarette finds no "crossroads" in Confucius. There is only one past, whereas there are many possible futures. The past is already there and cannot be changed, while the future is open (at least so it seems, a determinist might say). Thus if one is oriented toward the past, there will be no "crossroads", while regarding the future one has to make choices and to set up maxims for oneself to act upon. It must be admitted, though, that when looking into the past for orientation, one often finds more than one instance that one could take as a model and choose to follow. Thus one still has to reflect and to make choices. For the "Way without crossroads", see Herbert Fingarette, Confucius-The Secular as Sacred (New York: Harper \& Row Publishers, 1972), ch. 2. To avoid a wrong impression, it must be said that Fingarette sees Confucius as an innovator and not as turning to the past (ch. 4). He also thinks we should not look for an "inner" in Confucius (ch. 3). However, as much as I find his views interesting and thought provoking, I do not follow him in these two points. Compare note 1 , above. 
on the other hand, he took a position different from the rationalist tradition, inviting the idea that his views are closer to Confucius' in this domain. Thus aesthetics might appear to be a more suitable domain of comparison than ethics. ${ }^{22}$ But then the element of freedom, introduced and insisted on in Kant's aesthetics, standing as it does in opposition to the German rationalists' attempts to introduce objective rules of taste, must be squared with Confucius' views of rituals. This is likely not to be so easy, because with Kant's emphasis on freedom in his aesthetics, it is easier for him to move to modern art for instance, than is the case with Confucius.

Of the three elements of harmony in Confucius, mentioned above, only (2), the element of beauty through harmony with a past reality and of following ritual to re-introduce dao in our human activities, is absent in Kant. Instead, we might say, we find in Kant (2') the a priori principle of purposiveness; this is not about the past or about dao, but about nature as given. This principle explains beauty and bridges what appears to be a gap between morality and nature. Such a gap is absent in Confucius from the start, because no natural sciences had torn nature and morality apart. No Newton and no Galileo had created the threat of physical determinism against our feeling of moral freedom and agency. The absence of this threat for Confucius, and the absence of the views this threat gave rise to, creates the biggest difference between the two thinkers' conceptions of morality. This is why (2) is very different from (2'). For Kant, there must be two separate worlds, one of moral freedom and another of physical nature, the noumenal and the phenomenal, to escape this threat. At least there must be two very different perspectives. Not so for Confucius. In his view, we find dao penetrating everything, outer nature as well as humanity in us. The inner therefore has a very different flavor in Confucius.

Kant and Confucius take it as evident that morality and ren, respectively, are valuable and that one cannot argue for their value. Nevertheless, there remain differences between them. Kant gives an explanation for beauty through his analysis of the judgment of taste, but Confucius does no such thing. Kant also tries to explain how beauty is linked to morality, whereas Confucius does not. Confucius simply "relies" on the link, as we might say when applying Kant's theory. He recommends

22 For a discussion of Kant's emphasis on the role of feeling in aesthetics, in opposition to the rational tradition of his time, see Wenzel, An Introduction to Kant's Aesthetics, 4-7. 
the practice of rituals, not only pragmatically, counting on its order-creating function, but also aesthetically, relying on the harmony and beauty this practice creates. His intuitive idea that harmony and beauty "shine through" can be explained and justified if we have theories of aesthetic and moral reflection at our disposal as we find them in Kant. A further aspect of comparison between the two philosophers on the relationship between morality and aesthetics is that Confucius saw aesthetic qualities as refinements of moral ones, while Kant's ideas can be applied, as in Schiller, ${ }^{23}$ to develop the concept of an "aesthetic education". But this is a topic for a separate essay.

The a priori principle of purposiveness even offers a guarantee of some sort, not a guarantee for each individual case, but a guarantee in general, regarding the possibility for such a link between beauty and morality. For Kant, this was important, because it creates grounds for our hope for a better future and it involves not only aesthetics and morality, but also a science-oriented metaphysics. It involves not only subjective and objective, but also transcendental purposiveness. The latter can be seen only very dimly in Confucius, if at all, because there is no theory in Confucius comparable to the Kantian transcendental theory of a priori purposiveness. Again, there simply was no Leibniz or Newton in China. Even Aristotle's notion of $\vartheta_{\varepsilon \omega \rho} \alpha$ is far away from Confucius' thoughts. On the other hand, Confucius may not have been a transcendental realist either. His views of tian and dao, expressed sometimes with hesitation and sometimes with affirmation, can be seen as expressions of idealist intuitions-I do not mean skeptical intuitions about the existence of the external world as we find them in Berkeley, but positive intuitions about human values as we find them in Kant. The a priori principle of purposiveness can therefore be seen as a principle allowing us to explain the role of tian and dao in such intuitions in Confucius. $^{24}$

23 Friedich Schiller, On the Aesthetic Education of Man in a Series of Letters, tr. Elisabeth M. Wilkinson and L. A. Willoughby (Oxford: Clarendon Press, 1982[1967]).

24 I wish to thank my students from National Chi Nan University, Taiwan, for their questions and discussions during a course I gave on aesthetics in Kant and Confucius, and I wish to thank Philip J. Ivanhoe, Cheng Chung-Ying, Mihaela C. Fistioc, Shun Kwong-Loi, and James Peterman for pleasant conversations and helpful comments on earlier versions on this essay. 